\title{
Study on Thermoelectric Cooler Driven by Solar Energy in Medan City
}

\author{
Tulus. B. Sitorus ${ }^{1,2}$, Zulkifli Lubis¹, Farida Ariani1 ${ }^{1}$, Ferry Sembiring1 \\ ${ }^{1}$ Mechanical Engineering, Universitas Sumatera Utara, Medan \\ ${ }^{2}$ PUI Energi Berkelanjutan dan Biomaterial, USU Medan \\ Jl. Almamater Kampus USU, Medan - Indonesia \\ Email: zulkiflilubis123@yahoo.com
}

\begin{abstract}
The article aims to determine the performance of thermoelectric cooler driven by solar energy in Medan city. In a remote area where electricity is still not available can use this cooler box to store beverage such as drink cup so can maintain the freshness. The solar thermoelectric cooling system is based on the Peltier effect to create hot and cold side conditions. The cold side is used for cooling purposes to the cooling room. Heat from the heat side of the module is discharged into the surrounding environment using a heat sink and fan. Experimental results show that the solar thermoelectric cooler can reduce the drink cup temperature from $26^{\circ} \mathrm{C}$ to $15^{\circ} \mathrm{C}$ in about 40 minutes. The maximum COP of the cooling system during the experiment was calculated and found to be about 0.356 . The effect of weather conditions on the COP value was about $85.90 \%$.
\end{abstract}

Keywords: thermoelectric, drink cup, performance, solar energy

\section{INTRODUCTION}

The cooling system is an essential process for controlling the temperature of the product in industrial fields [1]. The conventional domestic refrigerators use the vapor compression cycle this time. The coefficient of performance (COP) of the refrigerators based on a vapor compression system is good enough, but the refrigerants used in such systems have problems in the global environment. Other cooling systems such as thermoelectric cooling based on the Peltier effect have essential advantages compared to conventional steam cycles even though the COP value is not as significant as the vapor compression systems [2]. Compared to vapor compression systems, thermoelectric cooling systems have the benefit of being free of refrigerants, shorter system, lower noise and vibration, good temperature control, and fewer maintenance requirements. [3]. Besides, they possess advantageous it can be powered by solar energy through photovoltaic cells $[4,5]$. The solar thermoelectric cooling is a particular cooler that uses solar energy as a substitute for conventional energy to drive thermoelectric equipment to be used to cool a room or object. In general, the components of 
a solar cooler system include thermoelectric modules, photovoltaic cells, cooling box, insulators, heat sinks, and cooling fans. The photovoltaic cells generate electrical energy to thermoelectric refrigeration. The research purpose to determine the performance of the thermoelectric cooling driven by solar energy.

\section{RELATED WORKS}

The thermoelectric cooling system is an electrical solid state refrigerant component that can serve as a heat pump for cooling. The principle is by using thermoelectric effect where the cold side is used for cooling purposes, and the hot side is used to release heat from the cold side to the environment by utilizing heat sink and fan [6]. On the side of the thermoelectric cooling system that absorbs heat, there is a cooling effect, and this is used for various cooling processes. Another term for thermoelectric cooling systems is Peltier cooling. The thermoelectric cooling system utilizes the Peltier effect that first discovered by Jean Charles Athanase Peltier in 1834. Briefly, it can be said that the Peltier effect is an effect of heat on one side and cooling effect on the other side when the direct current passed in a circuit of two different types of materials connected $[7,8]$. The material is a thermoelectric elemental material made from semiconductor material. In general, the advantages of a thermoelectric cooling system are practical because of their small shape, easy installation and does not involve complicated mechanical supports. This system can be applied to portable cooling devices, not easily damaged, during voltage, current and heat treatment accordingly with its provisions as well as predicted to be able to use thereabouts 100,000 hours. The drawback is the limited ability of cooling and low efficiency. Note that thermoelectric cooling system efficiency ranges from $10-15 \%[9,10]$. Applications which often use the thermoelectric cooling system are a cooling processor, air conditioning, refrigerator on the dispenser, beverage cooler, and temperature aquarium control. The COP value of thermoelectric refrigeration is the ratio between the resulting heat of the thermoelectric and the energy supplied. The COP value of thermoelectric cooling system can be determined from equation $[11,12]$ :

$\mathrm{COP}=\frac{\mathrm{Q}_{\text {cooling }}}{\mathrm{W}_{\text {in }}}$

Where the cooling capacity $(\mathrm{W})$ is

$\mathrm{Q}_{\text {cooling }}=\mathrm{m} \cdot \mathrm{C}_{\mathrm{p} . \Delta \mathrm{t}} \quad(\mathrm{W})$

and $W_{\text {in }}$ is energy supplied through photovoltaic cells $(\mathrm{W})$. 


\section{MATERIALS}

This study uses the TEC1-12706 thermoelectric module. The cooler use two batteries to provide power to the Peltier components. To provide a power supply to battery from solar energy then used two modules of the solar panel. The solar charge controller (SCC) with $12 \mathrm{~V}$ and $10 \mathrm{~A}$ is used to adjust the current for charging from solar panels to batteries to avoid overcharging and monitor the battery temperatures. The cooling box system is connected to a data acquisition system, Cole Parmer 18200-40 via a thermocouple which is set on the component. The temperature was measured using a J type thermocouple with an accuracy of $\pm 0.4 \%$. The HOBO micro station data recording device is used to record weather conditions such as radiation intensity, air temperature, and relative humidity. The environmental temperature and relative humidity $(\mathrm{RH})$ were measured using a HOBO sensor with an accuracy of $\pm 0.2^{\circ} \mathrm{C}$ and $\pm 2.5 \%$, respectively. A pyranometer with an accuracy of $\pm 5 \%$ is used to measure the intensity of solar radiation. As the local time, Medan city uses Western Indonesian Time or WIB (Waktu Indonesia Barat). The cooled objects used drink cups. The Peltier cooler box is isolated with $10 \mathrm{~mm}$ plywood on the outside, styrofoam with $40 \mathrm{~mm}$ in the middle and aluminum foil with $1 \mathrm{~mm}$ inside to minimize the influence of the air infiltration. The top cap is mounted bolts that can be opened-close to seal the cover of the cooling box further.

\section{THE LAYOUT EXPERIMENTAL}

The experimental process was done starting at 09.00 WIB with the power supply the battery begins to be activated and deactivated at 17.00 WIB. The battery is activated by connecting the cable from the SCC to the battery for eight hours so that the acquisition data can record the temperature changes that occur. The dimension of cooler box namely length $36 \mathrm{~cm}$, wide $28 \mathrm{~cm}$, and height $26 \mathrm{~cm}$. The type of Peltier used is four pieces of TECl-12706. The Peltier components comprise four heatsink, four cold sinks, and four small fans. This experiment uses two pieces (@100 W) of the photovoltaic cells. The thermoelectric cooler is deactivated at $17.00 \mathrm{WIB}$ and data of temperature changes have been obtained. The test on the next day again repeated with the same procedure starting at 09.00 WIB. The experiments were conducted for five consecutive days in February 2018 in Medan city. Figure 1 shows the outside and inside of the solar thermoelectric cooler tested. Figure 2 shows the experimental scheme of this research. 


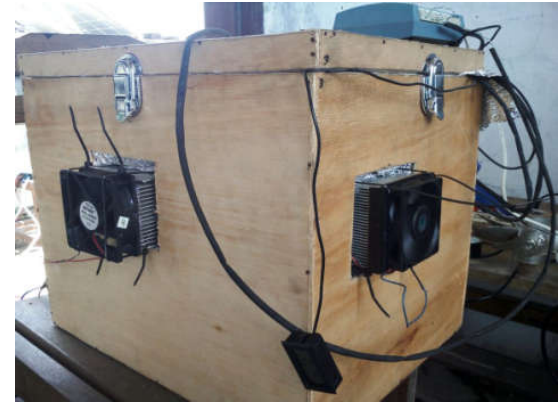

(a)

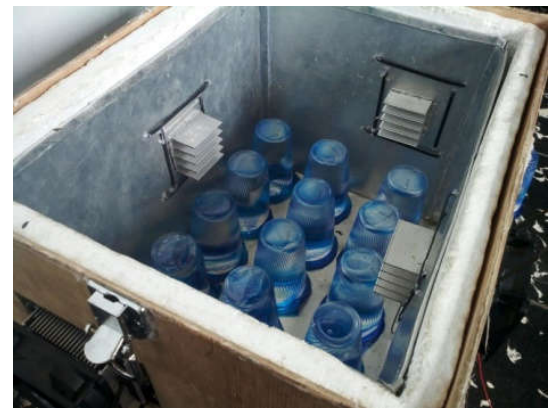

(b)

Figure 1. (a) The outside of a cooler box

(b) The inside of a cooler box

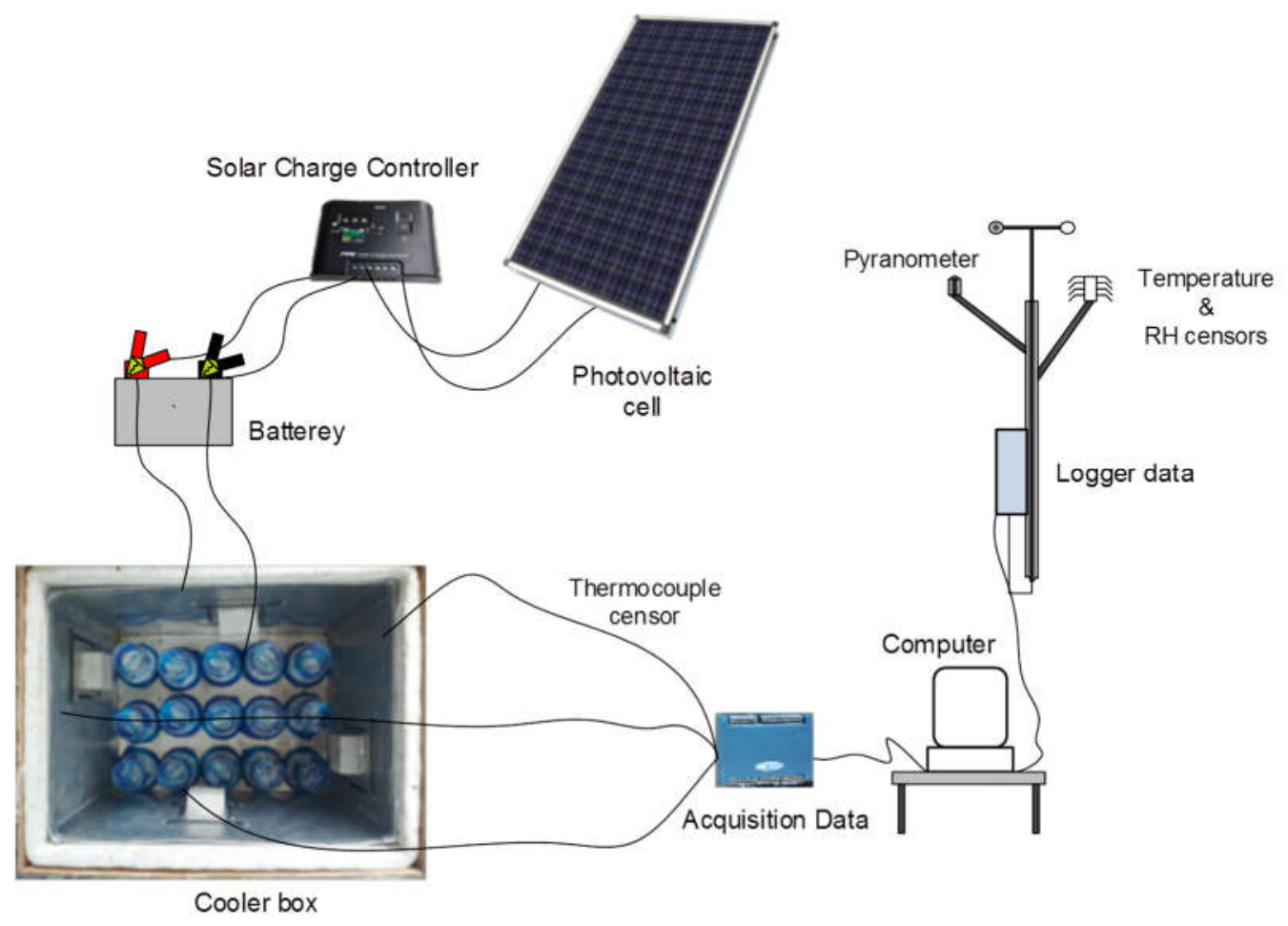

Figure 2. The layout experimental

\section{EXPERIMENT AND ANALYSIS}

\subsection{Weather Condition}

The tests are carried out in open locations that experience direct solar radiation. The weather conditions need to be known because relate to the performance of the photovoltaic cells used. The photovoltaic cells absorb the energy of solar radiation and stored into batteries. The battery power uses to drive the Peltier components in the cooling process. The process of measuring the weather conditions is carried out in five days. The measurement time range is done in one minute. Table 1 shows the weather conditions parameters during experiments. 
Table 1. Weather conditions during experiments

\begin{tabular}{|c|c|c|c|}
\hline Day & $\begin{array}{c}\text { Average } \\
\text { ambient temperature } \\
\left({ }^{\circ} \mathrm{C}\right)\end{array}$ & $\begin{array}{c}\text { Average } \\
\text { relative humidity } \\
(\%)\end{array}$ & $\begin{array}{c}\text { Average } \\
\text { solar radiation } \\
\left(\mathrm{W} / \mathrm{m}^{2}\right)\end{array}$ \\
\hline 1 & 29.65 & 63.06 & 187.23 \\
\hline 2 & 29.11 & 79.21 & 178.22 \\
\hline 3 & 28.97 & 81.87 & 165.32 \\
\hline 4 & 29.78 & 77.11 & 162.44 \\
\hline 5 & 28.34 & 82.21 & 166.35 \\
\hline
\end{tabular}

The measured weather parameters were temperature, humidity, and solar radiation intensity. The conditions of radiation measurements and solar radiation on theoretical calculations on the first day is shown in figure 3 . There is a difference of results because in the calculation of solar radiation simulation results assumed that the condition of the sky is bright while on the measurement result is the actual condition of the sky can be sunny and cloudy. Based on the experimental data obtained from the measurement results that generally the solar radiation appear from 06.20-18.32 WIB for five days of experiments.

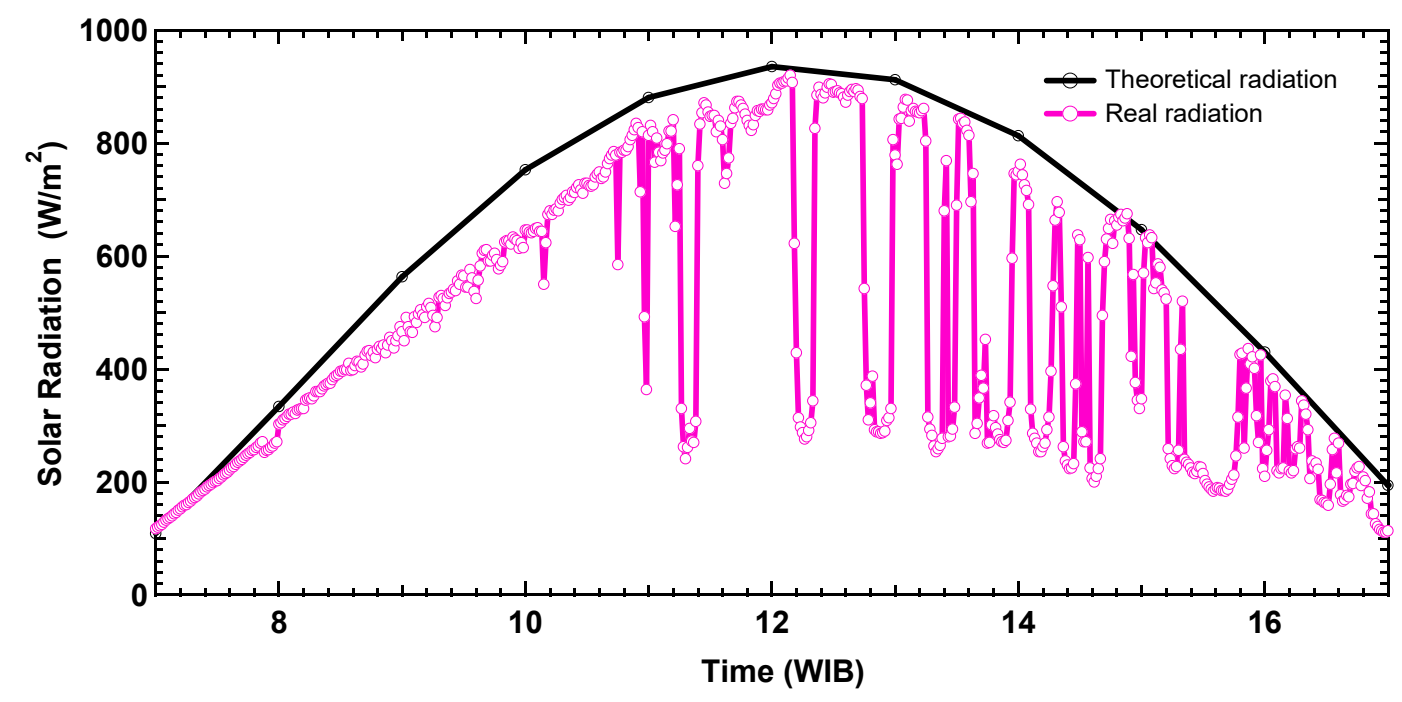

Figure 3. Typical of the intensity of solar radiation in the first day

\subsection{Photovoltaic Performance}

The Peltier refrigeration system uses solar cell panel components to absorb solar radiation to generate electrical energy. To calculate the estimated power of PV modules required it is necessary to know the average power needed by the cooling system every day. The electronic equipment used in the cooler is four small fans with a power of 1.8 watts each and four thermoelectric type TEC1-12706 with a power of each 72 watts. Average 
electricity usage for 8 hours for one day is 2361Wh. Since the electricity usage of PV is $100 \%$, then the required PV output per day is $2361 \mathrm{Wh}$. As a note that for the calculation of power estimation power is then assumed the conditions of sunny weather with the intensity of solar radiation an average of 8 hours per day. In this study, also used batteries that serve to store electrical energy that has been generated by PV modules and used as an energy source to drive the fan and Peltier components. The battery used has a specification of $12 \mathrm{~V}, 70 \mathrm{Ah}$. The value of voltage and current coming out of solar panels ranges from $18.9 \mathrm{~V}$ and $5.3 \mathrm{~A}$ which is set by SCC to 12 Volt and 10 A to charge 70 Ah battery.

\subsection{The Solar Thermoelectric Cooler Performance}

To know the temperature variations of the thermoelectric cooling system is tested by placement of thermocouple sensors at multiple points in the cooler. The thermocouple sensor is located outside of the cooler for the ambient temperature, the top cover wall, the left wall, the right wall, the lower wall, and the cooled objects. The experiments conducted on starting at 09.00 WIB until 17.00 WIB for eight hours. The tests were performed for five days with varying weather conditions. Figures 4 up to 8 show the temperature distribution of the cooling wall and cooled objects during experiments.

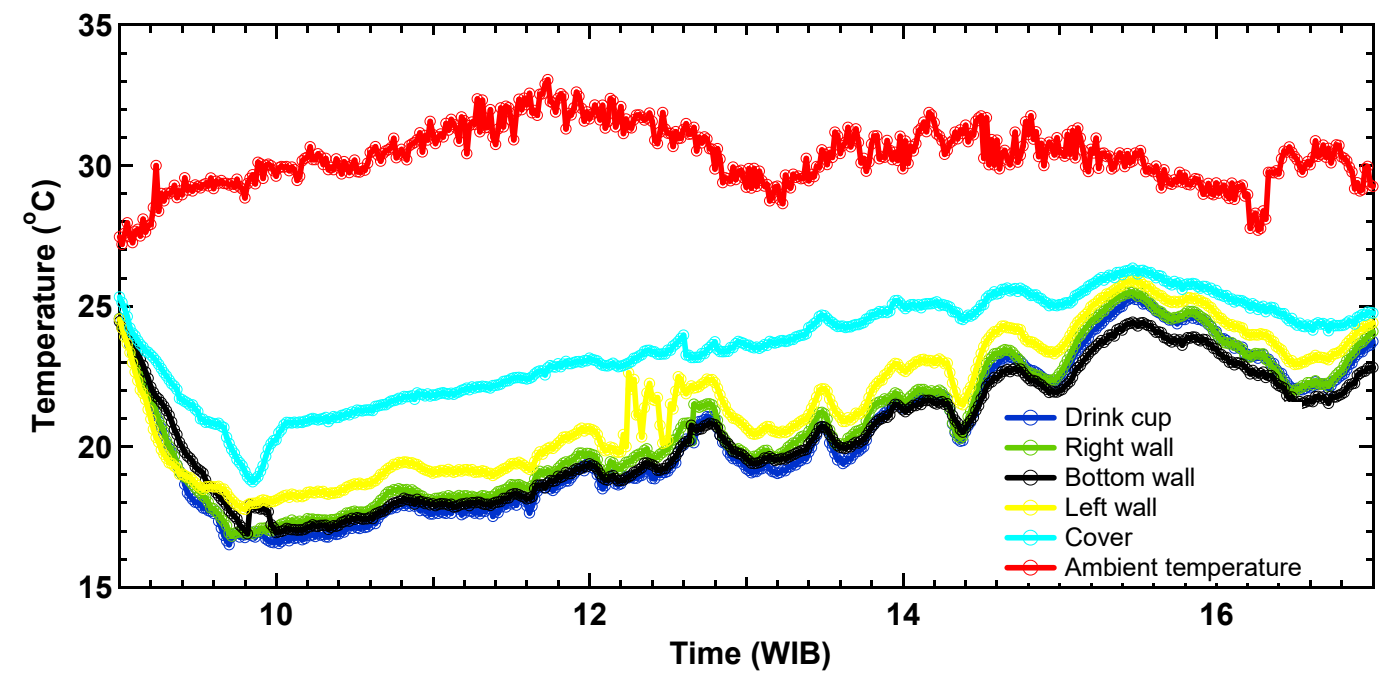

Figure 4. Temperature distribution in the cooler on the first day 


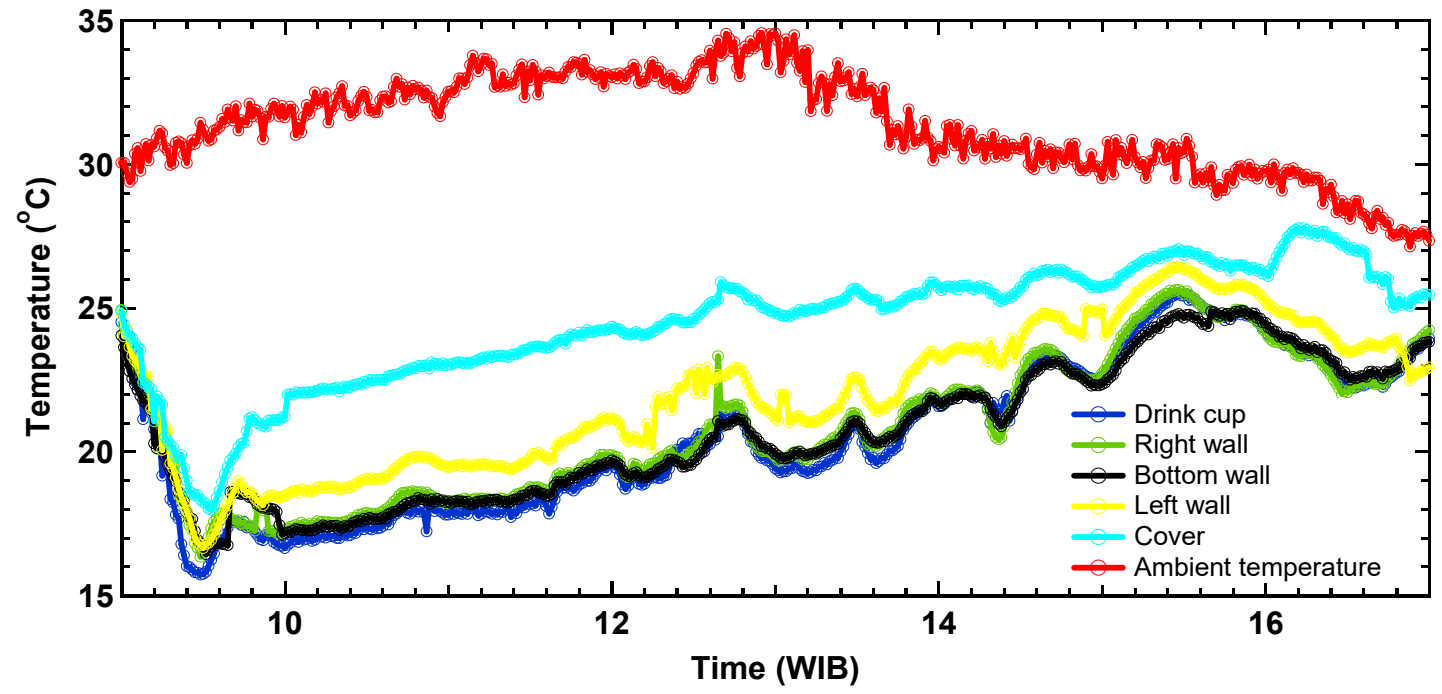

Figure 5. Temperature distribution in the cooler on the second day

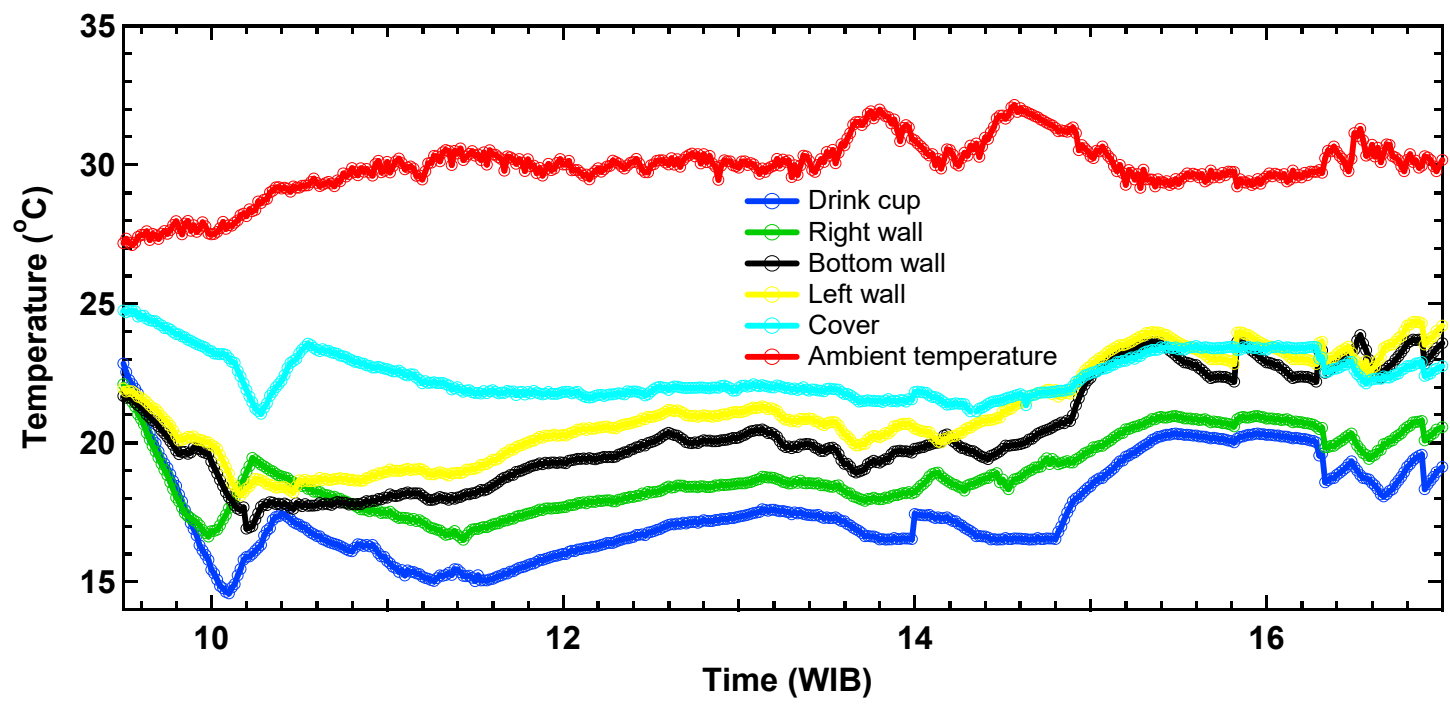

Figure 6. Temperature distribution in the cooler on the third day 


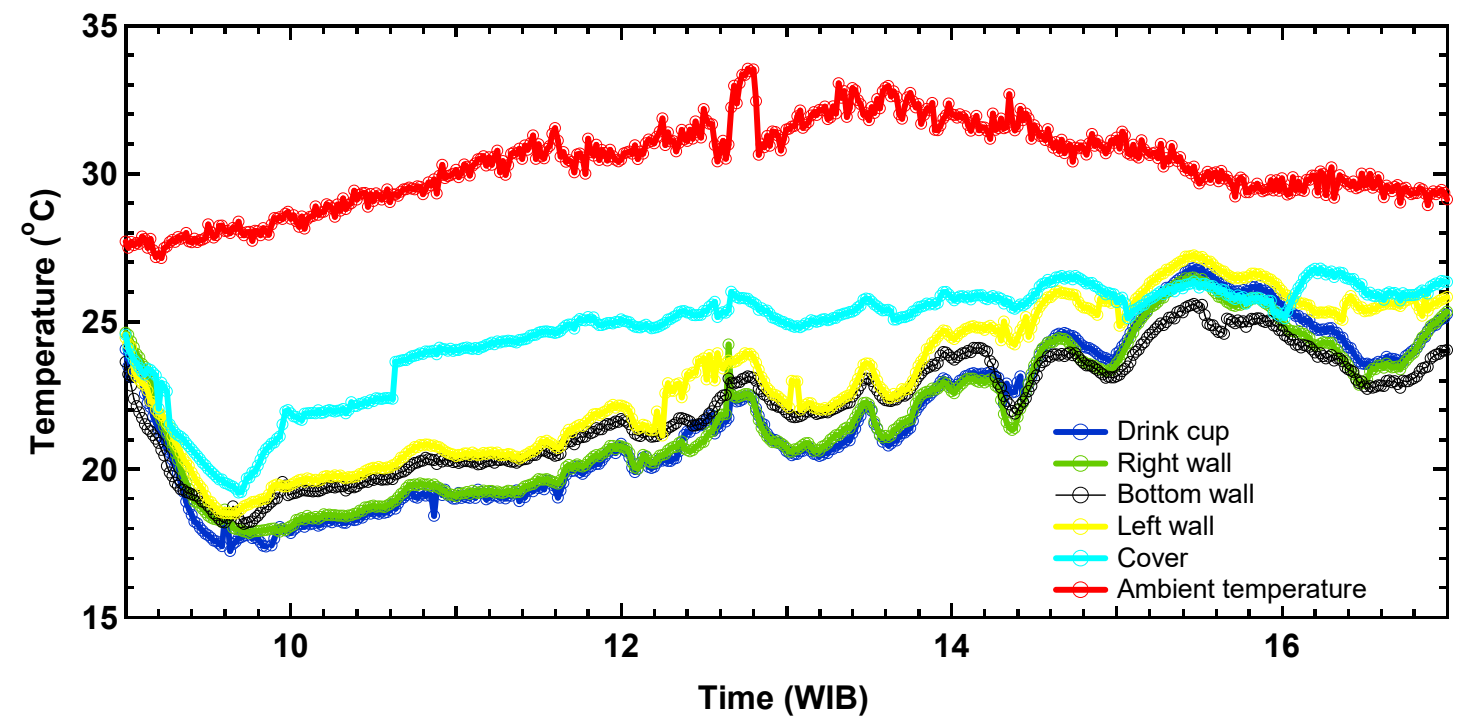

Figure 7. Temperature distribution in the cooler on the fourth day

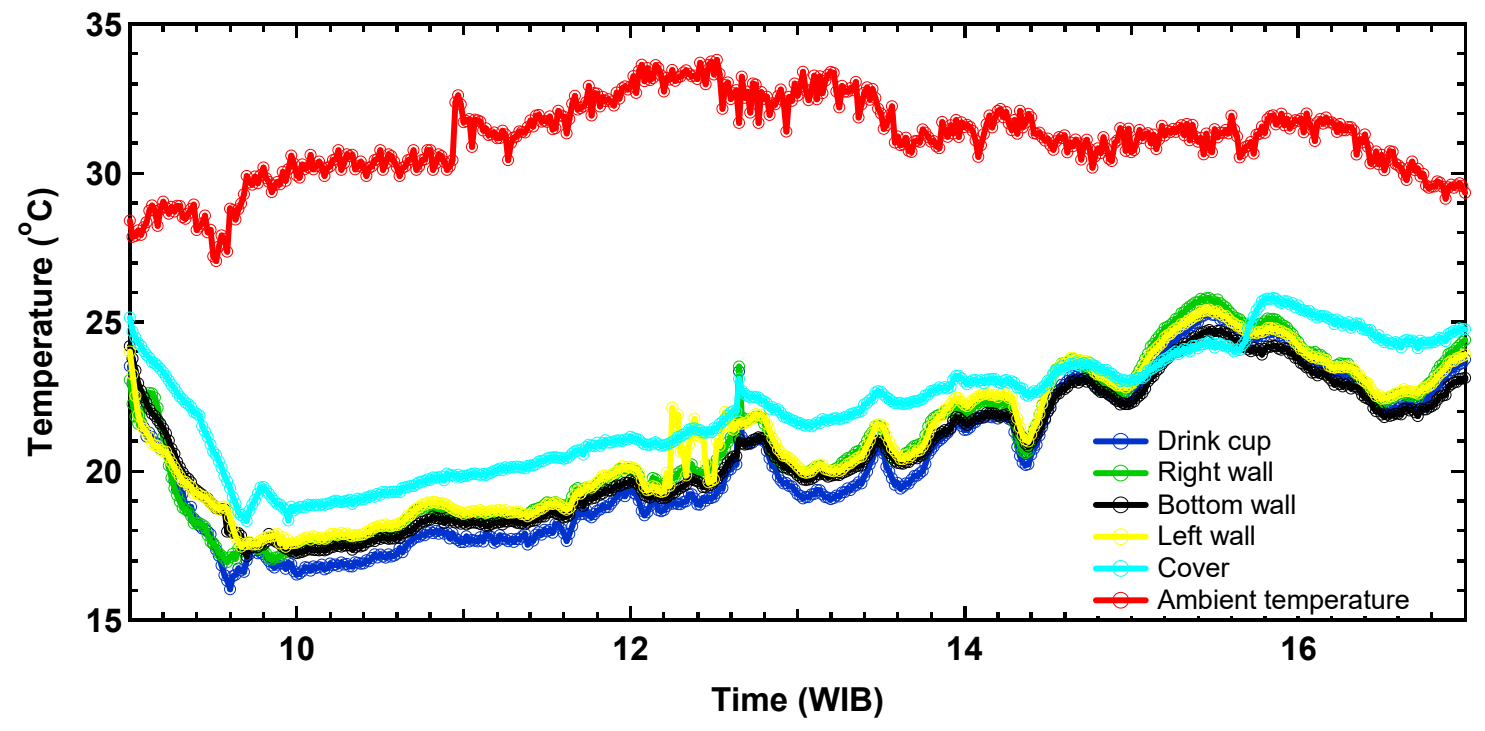

Figure 8. Temperature distribution in the cooler on the fifth day

Measurements are made on the inside and outside of the Peltier cooler system. The inside of the cooler box measured is the temperature on the left wall, the right wall, the lower wall, the top cover wall, and the drink cup. The outside is the outer top wall of the cooler box that directly experience exposure to sunlight.

During experiments, the minimum temperature of the drink cup was $16.51^{\circ} \mathrm{C}$, $15.72^{\circ} \mathrm{C}, 14.57^{\circ} \mathrm{C}, 17.24^{\circ} \mathrm{C}$ and $16.03^{\circ} \mathrm{C}$, respectively. The minimum temperature of the drink cup was obtained at $14.57^{\circ} \mathrm{C}$ on the second day with an average environment temperature of $31.34^{\circ} \mathrm{C}$. Generally, the minimum temperature on drink cup is obtained at 09.15-10.00 WIB. The average 
temperature of the drink cup during the experiments was $20.30^{\circ} \mathrm{C}$ and $20.32^{\circ} \mathrm{C}$. The inner wall temperature of the cooling box during tests ranges from $16-26^{\circ} \mathrm{C}$. The measurement results show that the average temperature of the outside air on the first day until the fifth day is $30.54^{\circ} \mathrm{C}$. The experimental data shows that the maximum air temperature achieved during the experiments was $33.79^{\circ} \mathrm{C}$ which occurred on the fourth day. In general, there is a difference in the temperature distribution that occurs at the point of the measured component. It can be seen from the figures 5 up to 8 that the temperature distribution on the upper wall is higher than the temperature distribution on the left, right, and bottom walls. This is influenced by the distance of heat sink components closer to the left wall, right and bottom. The experimental data shows that the measuring point on the outer wall of the cooler box has the highest temperature compared to the other measuring point which is caused by the influence of the air temperature and the effect of heat discharged by the fan from the heat sink attached to the surrounding environment. The results indicate that the temperature distribution in the cooler is quite evenly distributed to all sides of the cooler. This can be seen from the temperature difference between the measurement points ranging from $0.023-0.231^{\circ} \mathrm{C}$. The difference in mean temperature inside and outside of the cooler is about $9-12^{\circ} \mathrm{C}$. This condition indicates the process of heat dissipation contained in the cooler so that there is a cooling effect on the cooled object that drinks cup placed in the cooler. The experimental data also show that in general for five days of experiments there is an increase in temperature of the components measured in the cooler starting at 12.00 WIB. An analysis of the temperature increase in the cooler may be due to several factors. First, the rise in air temperature outside the cooler that also influences the temperature change condition inside the cooler. Second, the time operation of the fan long enough can lead to the emergence of heat in the cooling system. Third, the reduced power on the battery as energy supply to drive the fan and Peltier components on the cooler so that the thermoelectric element is not working optimally. The COP value of thermoelectric cooling box obtained during experiments as shown in table 2 .

Table 2. The COP value during experiments

\begin{tabular}{|c|c|c|c|c|}
\hline Day & $\begin{array}{c}\text { Initial } \\
\text { temperature } \\
\left({ }^{\circ} \mathrm{C}\right)\end{array}$ & $\begin{array}{c}\text { Minimum } \\
\text { temperature } \\
\left({ }^{\circ} \mathrm{C}\right)\end{array}$ & $\begin{array}{c}\text { Cooling } \\
\text { time } \\
\text { (minute) }\end{array}$ & COP \\
\hline 1 & 26.77 & 16.51 & 53 & 0.190 \\
\hline 2 & 26.76 & 15.72 & 40 & 0.356 \\
\hline 3 & 26.95 & 14.57 & 55 & 0.213 \\
\hline 4 & 26.86 & 17.24 & 49 & 0.209 \\
\hline 5 & 26.78 & 16.03 & 47 & 0.254 \\
\hline
\end{tabular}

The maximum COP value that can be obtained is 0.356 on the second day with a cooling time of 40 minutes. The average COP values obtained during 
the experiments is 0.245 and the cooling time to achieve a minimum temperature range from 40 to 55 minutes. The effect of weather conditions on the COP value is verified using a multiple regression analysis systems. The statistical analysis results show that the coefficient of determination $\left(\mathrm{R}^{2}\right)$ is 0.859 , which means that the influence of weather conditions on the COP value is around $85.90 \%$.

\section{CONCLUSION}

In the study, the solar thermoelectric cooling unit was made and tested. Cooling performance testing is carried out under bright outdoor conditions. It was found that the performance of the cooling system is very dependent on the intensity of solar radiation and the temperature difference between the hot and cold sides of the thermoelectric component. The maximum temperature difference between the cooling box inside and outdoor conditions is close to $19^{\circ} \mathrm{C}$. The COP of the solar thermoelectric cooler, based on the material and technology available today is still lower than the cooling system that uses compressors. However, through several improvements, the solar thermoelectric cooling system will be acceptable in the future.

\section{Acknowledgments}

The authors are grateful to DRPM DIKTI through PTUPT research grant in 2018.

\section{REFERENCES}

[1] Murat Gökçek, Fatih Şahin, Experimental performance investigation of mini-channel water cooled-thermoelectric refrigerator, Case Studies in Thermal Engineering 10, 54-62, 2017.

[2] Sitorus T.B., Napitupulu F.H., Ambarita H., Experimental Study of Solar Refrigerator System Using Activated Alumina and Methanol Adsorption Pair, International Journal of Technology 5: 910-922, ISSN 2086-9614, 2016.

[3] Sitorus T.B., Napitupulu F.H., Ambarita H., A Study on Adsorption Refrigerator Driven by Solar Collector Using Indonesian Activated Carbon, Journal of Engineering and Technological Sciences, Vol. 49, No. 5, 657-670, 2017.

[4] Rahnuma Siddiqui et al., Comparison of different technologies for solar PV (Photovoltaic) outdoor performance using indoor accelerated aging tests for long-term reliability, Energy 107, 550561, 2016.

[5] Abdul Muhaimin Ismail et al., Progress of solar photovoltaic in ASEAN countries: A review, Renewable and Sustainable Energy Reviews 48, 399-412, 2015. 
[6] Bosen Qian, Fei Ren, Cooling performance of transverse thermoelectric devices, International Journal of Heat and Mass Transfer 95, 787-794, 2016.

[7] Ravi Ranch, Manoj Kumar, Brijesh Tripathi, Solar Photovoltaic System Design Optimization by Shading Analysis to Maximize Energy Generation from Limited Urban Area. Energy Conversion and Management 115, pp. 244-252, 2016.

[8] Xi H, Luo L, Fraisse G., Development and applications of solarbased thermoelectric technologies, Renew Sustain Energy Rev; 11:923-36, 2007.

[9] Martinez, D. Astrain, A. Rodriguez, P. Aranguren, Advanced computational model for Peltier effect based refrigerators, Applied Thermal Engineering 95, 339-347, 2016.

[10] Yan-Wei Gao, Hao L, Xiao-Dong Wang, Wei-Mon Yan, Enhanced Peltier cooling of two-stage thermoelectric cooler via pulse Currents, International Journal of Heat and Mass Transfer 114, 656663, 2017.

[11] Eun Soo Jeong, Optimization of conduction-cooled Peltier current leads, Cryogenics 45, 516-522, 2005.

[12] Christian J.L. Hermes, Jader R. Barbosa Jr., Thermodynamic comparison of Peltier, Stirling, and vapor compression portable coolers, Applied Energy 91, 51-58, 2012. 